\title{
ASPECTOS JURÍDICOS DE HOMICÍDIO CAUSADO POR EMBRIAGUEZ AO VOLANTE
}

Pedro Victor De Souza Pavezi, Airton Rodrigo Guelfi.

Universidade do Oeste Paulista - UNOESTE, Curso de Direito, Presidente Prudente, SP. E-mail: pedropavezi@icloud.com

\section{RESUMO}

O presente artigo visa mostrar os aspectos jurídicos de homicídio causado por embriaguez ao volante, trazendo julgados, leis e entendimento doutrinário ao respectivo assunto. Atualmente, observa-se que, o judiciário brasileiro tem dois aspectos diferentes para crime de homicídio causado por embriaguez ao volante, sendo o primeiro aspecto de homicídio culposo, disposto no caput do artigo 302 do Código de Trânsito Brasileiro. Por outro lado, visa-se o homicídio doloso, este grafado no artigo 121 do Código Penal, considerando-se como dolo eventual, ou seja, o autor assume o risco e segue na execução do inter criminis, tendo como pena mais severa que a do artigo 302 do Código de Trânsito Brasileiro. Por fim, o mero trabalho trás decisões de tribunais superiores brasileiros, também aborda as decisões majoritárias e minoritárias, e a que vem mais se aplicando nas decisões finais.

Palavras - chave: Embriaguez ao Volante. Homicídio Culposo. Homicídio Doloso. Decisão Majoritária e Minoritária.

\section{LEGAL ASPECTS OF HOMICIDE CAUSED BY FLIGHT EMBRYGUEZ}

\section{ABSTRACT}

This article aims to show the legal aspects of homicide caused by drunken driving, bringing judgments, laws and doctrinal understanding to the respective subject. Currently, it is observed that the Brazilian judiciary has two different aspects to crime of homicide caused by drunken driving, the first aspect of manslaughter, set out in the caput of article 302 of the Brazilian Traffic Code. On the other hand, it is intended the intentional homicide, the one written in article 121 of the Criminal Code, considering as possible fraud, that is, the author assumes the risk and follows in the execution of the inter criminis, having as punishment more severe than the of article 302 of the Brazilian Traffic Code. Finally, mere work brings decisions from Brazilian higher courts, it also addresses majority and minority decisions, and the one that is most applied in final decisions.

Keywords: Drunk Driving. Manslaughter. Dolly Homicide. Majority and Minority Decision. 


\section{DIREITO A VIDA}

Para o nosso ordenamento jurídico a vida é um direito fundamental consagrado pela Constituição, havendo diversos dispositivos que demonstram o quão importante é este bem jurídico:

Primeiro o art. 5 de nossa Carta Magna:

Art. 5o Todos são iguais perante a lei, sem distinção de qualquer natureza, garantindo-se aos brasileiros e aos estrangeiros residentes no País a inviolabilidade do direito à vida, à liberdade, à igualdade, à segurança e à propriedade, nos termos seguintes: (grifo nosso).

Segundo Moraes (2005, p.30), “o direito a vida é cardealmente o mais fundamental dos direitos: o direito à vida é o mais fundamental de todos os direitos, já que se constitui em prérequisito à existência e exercício de todos os demais1".

Deste modo, a vida, logo, por ser direito fundamental protegido por nossa Carta Magna, deve se, por si própria, ser interrompida unicamente por causas naturais, proibindo-se que outrem tire vidas no trânsito de outras pessoas, ora que, o Estado deve assegurar tais garantias a todos, para garantir ao mesmo tempo, respectivo direito à vida. Porém, fatos que tornam à vida o direito principal existente, sendo-o primeiro a ser protegido.

\section{A MORTE DECORRENTE DE ACIDENTE DE TRÂNSITO CAUSADO POR MOTORISTA EMBRIAGADO.}

Hodiernamente, o cenário jurídico brasileiro mantém um debate sobre o a morte causada por acidentes de trânsito onde o fator embriaguez ao volante representar elemento fundamental da conduta. Assim, o cerne desta discussão gira em torno do seguinte questionamento: em qual tipificação ele se enquadra?

\section{A FIGURA CULPOSA}

No Código de Trânsito Brasileiro, junto ao artigo 302, § 3‥ (BRASIL.1997), encontramos a figura típica do "homicídio culposo na direção de veículo automotor", com a seguinte redação:

Art. 302. Praticar homicídio culposo na direção de veículo automotor:

Penas - detenção, de dois a quatro anos, e suspensão ou proibição de se obter a permissão ou a habilitação para dirigir veículo automotor.

§ 3o Se o agente conduz veículo automotor sob a influência de álcool ou de qualquer outra substância psicoativa que determine dependência: (Incluído pela Lei no 13.546, de 2017) (Vigência)

Penas - reclusão, de cinco a oito anos, e suspensão ou proibição do direito de se obter a permissão ou a habilitação para dirigir veículo automotor. (Incluído pela Lei no 13.546 , de 2017) (Vigência).

De acordo com artigo jurídico na nobre revista conceito jurídico pag. $27 / 28^{2}$, as atualizações recentes da referida lei, que entrou em vigor no dia 18 de abril de 2018 (vacatio legis de 120 dias), faça com que o legislador penal, ao definir uma pena mais branda para quem, com efeito de álcool mata alguém culposamente no trânsito, com pena de cinco a oito anos, além da pena privativa de liberdade, o motorista perde o direito de dirigir por tempo a ser determinado pelo magistrado no momento da sentença. De acordo com as novas penas, no caso de homicídio culposo, o infrator, se primário, poderá vir a iniciar o cumprimento da pena em regime semiaberto, ainda que, continua aplicável a substituição da pena por restritiva de direito, por ser crime de caráter culposo (art. 44, inc. 1, parte final do Código Penal).

Nesta modalidade o condutor não precisa estar somente em vias públicas para ser caracterizado o crime, o crime ocorrerá em qualquer via, sendo, o bem jurídico tutelado a vida e

\footnotetext{
${ }^{1}$ Alexandre de Moraes é um jurista, magistrado e ex-politico brasileiro, atual ministro do Supremo Tribunal Federal e Preside a Primeira Turma do Supremo Tribunal Federal.

${ }^{2}$ Euro Bento Maciel Filho é advogado e professor de Direito Penal e Processo Penal, mestre em Direito Penal ar pela PUC-SP e sócio do escritório Euro Filho Advogados Associados. 
segurança viária, onde o sujeito ativo pode ser qualquer pessoa, com ou sem permissão para dirigir, basta estar na posse do veículo automotor.

Deve se fazer uma analise das circunstâncias para identificar se o condutor agiu da forma culposa, Estefam (2015, p. 130) descreve que:

[...] É de fundamental importância definir se o fato se subsume ao Código Penal ou ao Código de Trânsito, até porque a sanção neste é mais elevada (detenção, de dois a quatro anos, e suspensão ou proibição de se obter a permissão ou habilitação para dirigir veículo automotor), sem falar das causas de aumento (um terço à metade) específicas para este crime, contidas no parágrafo único do art. 302 (" não possuir Permissão para Dirigir ou Carteira de Habilitação; praticá-lo em faixa de pedestres ou na calçada; deixar de prestar socorro, quando possível fazê-lo sem risco pessoal, à vítima do acidente; no exercício de sua profissão ou atividade, estiver conduzindo veículo de transporte de passageiros")[...]

Seguindo a erudição, o Ministro Paulo Medina, da Sexta Turma do Superior Tribunal de Justiça (STJ) no ano de 2006, desclassifica a conduta para homicídio culposo, fortalecendo a decisão para esse tipo de crime como homicídio culposo:

ACIDENTE AUTOMOBILÍSTICO. DOLO EVENTUAL. IN DUBIO PRO SOCIETATE. DESCABIMENTO.

A Turma proveu o recurso ao entendimento de que inexiste o dolo eventual no acidente causado por motorista que, no estado de embriaguez, dirigia de madrugada seu veículo com excesso de velocidade. Descaracterizado o princípio in dubio pro societate. Desclassificada a conduta do réu para a forma culposa, por falta de elemento convincente a caracterizar a prática do homicídio doloso (arts. 18, I e II, e 121, caput, do Código Penal c/c art. 302 da Lei n. 9.503/1997). Precedente citado: REsp 765.593-RS, DJ 19/12/2005. REsp 705.416-SC, Rel. Min. Paulo Medina, julgado em 23/5/2006.

Em julgado, o Ministro do caso, levou em conta as circunstâncias do crime, analisando os elementos convincentes para a caracterização da prática do crime. No caso em concreto deste julgado houve como elemento a falta da realização de vontade para que incriminasse dolosamente o infrator do fato, sendo assim, o jurista vem a descaracterizar o princípio in dúbio pro societate que identificava como homicídio doloso.

$\mathrm{Na}$ falta dos elementos e circunstâncias que incriminem o acusado para a prática delituosa, não tem do que, aplicar uma pena mais branda para o crime cometido, e consequentemente, vem a manter a linha de raciocínio do Código de Trânsito Brasileiro.

Conclua-se que, na falta de provas contundentes, que vem a provar que a vontade do resultado final do agente, não seja intencional, deve-se julgar de forma lapsa, em concordância com as palavras de Bittencourt (2014): é inobservância do dever objetivo de cuidado manifestado numa conduta produtora de resultado não querido, objetivamente previsível ${ }^{3}$. Determina-se, nessa linha de pensamento, sentenciar como homicídio culposo, tipificado no art. 302 do Código de Trânsito Brasileiro.

\section{A FIGURA DOLOSA}

Por outro lado, o Código Penal traz em seu artigo 121 a figura do homicídio doloso:

Art. 121. Matar alguém:

Pena - reclusão, de seis a vinte anos. (grifo nosso)

Conforme demonstrado, o crime de homicídio praticado com embriaguez ao volante vem se tornando algo mais discutido nos dias atuais da sociedade, gerando uma incerteza quanto à segurança de sair da própria residência para o serviço, estudos e a meros passeios, onde o automóvel acaba se tornando em alguns casos como uma arma fatal, por descuido do condutor em assumir a direção do veiculo automotor em estado de embriaguez.

\footnotetext{
${ }^{3}$ Cezar Roberto Bittencourt é, Doutor em Direito Penal (Universidade de Sevilha, Espanha). Advogado e Professor Universitário. Colloquium Socialis, Presidente Prudente, v. 02, n. Especial 2, Jul/Dez, 2018, p.162-167. DOI: 10.5747/cs.2018.v02.nesp2.s0272
} 
Quanto a esses crimes praticados, o tribunal vem julgando de duas formas aonde a pena vem a serem bem distintas uma da outra, sendo-a primeira já estudada, de pena mais sucintas, regrada no art. 302 do CTB de caráter culposo, de outro modo, é reconhecido, a pratica dolosa para estes crimes, tendo penas maiorais, na qual, vem ganhando mais forças nas decisões dos tribunais brasileiros.

Para alguns magistrados e doutrinadores temos outro entendimento para o crime, sendo o de dolo eventual, cometido por embriaguez na condução de veiculo automor, diga-se de passagem, que este vem sendo considerado como uma posição majoritária de julgados, sendo analisadas através das teorias, como explica Bitencourt (2014, p. 65):

Existem a teoria da vontade, onde o agente deseja o resultado e vai em busca dele, e a teoria da representação, onde o agente não deseja diretamente o resultado, no caso de homicídio "matar", mas assume o risco e entende que a probabilidade é de sua ocorrência. A consciência do risco difere da vontade de obtê-lo. Como ensina o autor: As divergências entre as duas teorias anteriores foram consideravelmente atenuadas pela teoria do consentimento, chegando-se à conclusão de que o dolo é, ao mesmo tempo, representação e vontade. Para essa teoria, também é dolo a vontade que, embora não dirigida diretamente ao resultado previsto como provável ou possível, consente na sua ocorrência ou, o que dá no mesmo, assume o risco de produzi-lo. A representação é necessária, mas não suficiente à existência do dolo, e consentir na ocorrência do resultado é uma forma de querê-lo.

Caracteriza-se como dolo eventual quando o agente assume os riscos que podem ser causados através de atos futuros. Sendo que, a consciência; logo, aceita a possibilidade sem se importar com o possível risco a ser cometido.

Desse modo, a pratica do crime como dolo eventual, vem ganhando mais forças nos tribunais, onde adotam esse pensamento para crimes de homicídio causado por embriaguez ao volante, e vemos que, a posição majoritária defende que há "dolo eventual" na conduta daquele que embriagado e conduzindo veículo automotor, venha provocar a morte de um terceiro. $\mathrm{E}$ respondendo pelo crime de "homicídio doloso", vejamos a decisão do Superior Tribunal de Justiça, com o Relator Ministro Jorge Mussi, julgado de 12/04/2011:

COMPETÊNCIA. JÚRI. ACIDENTE. TRÂNSITO. HOMICÍDIO.

Trata-se de acidente de trânsito fatal com duas vítimas e quatro lesões corporais segundo consta dos autos, o recorrente, no momento em que colidiu com outro veículo, trafegava em alta velocidade e sob a influência de álcool. Por esse motivo, foi denunciado pela suposta prática dos delitos previstos nos arts. 121, caput, por duas vezes e 129 por quatro vezes, ambos do $\mathrm{CP}$, e pronunciado para ser submetido a julgamento no tribunal do júri. Ressalta o Min. Relator que o dolo eventual imputado ao recorrente com submissão ao júri deu-se pela soma de dois fatores: o suposto estado de embriaguez e o excesso de velocidade. Nesses casos, explica, o STJ entende que os referidos fatores caracterizariam, em tese, o elemento subjetivo do tipo inerente aos crimes de competência do júri popular. Ademais, a atribuição de indícios de autoria e da materialidade do delito foi fundamentada nas provas dos autos, não sendo possível o reexame em REsp (óbice da Súm. n. 7-STJ). Quanto à desclassificação do delito de homicídio doloso para o crime previsto no art. 302 do CTB - conforme a alegação da defesa, não está provada, nos autos, a ocorrência do elemento subjetivo do tipo (dolo) -, segundo o Min. Relator, faz-se necessário aprofundado exame probatório para ser reconhecida a culpa consciente ou o dolo eventual, pois deve ser feita de acordo com as provas colacionadas. Assim, explica que, além da vedação da citada súmula, conforme a jurisprudência, entende-se que, de acordo com o princípio do juiz natural, o julgamento sobre a ocorrência de dolo eventual ou culpa consciente deve ficar a cargo do tribunal do júri, constitucionalmente competente para julgar os crimes dolosos contra a vida. Dessa forma, a Turma negou provimento ao recurso, considerando que não houve ofensa aos arts. 408 e 74, § 1ㅇ, do CPP nem ao art. 302, parágrafo único, V, da Lei n. 9.503/1997, diante de indícios suficientes de autoria e da materialidade delitiva. Quanto à reavaliação desses elementos, isso não seria possível em REsp, pois incide a citada súmula, bem como 
não cabe o exame de dispositivo da CF. Precedentes citados: HC 118.071-MT, DJe 19/2/2011; REsp 912.060-DF, DJe 10/3/2008; HC 26.902-SP, DJ 16/2/2004; REsp 658.512GO, DJe 7/4/2008; HC 36.714-SP, DJ 10/7/2005; HC 44.499-RJ, DJ 26/9/2005; HC 91.397SP, DJe 15/12/2008, e HC 60.942-GO, DJ 29/10/2007. REsp 1.224.263-RJ, Rel. Min. Jorge Mussi, julgado em 12/4/2011.

Conforme raciocínio do relator faz-se por necessário exame probatório para ser distinguida a culpa consciente do dolo eventual junto as provas colecionadas, neste sentido, na decisão restou entendido como dolo eventual pelas provas da embriaguez ao volante e alta velocidade.

Em ultima analise, a consequência para esta prática ilícita vem se radiando na posição do dolo eventual para aqueles que causam a morte de outrem através da conduta de conduzir veículo automotor em estado de embriaguez.

\section{CONCLUSÃO}

Deste modo, percebe-se que no atual cenário jurisdicional brasileiro há duas correntes distintas quanto ao julgamento do crime de homicídio cometido por conduzir veiculo automotor sob a influência de álcool: de um lado o entendimento de Homicídio Culposo, quando o agente não tem a intenção de matar, culpa inconsciente, sendo está convicção uma decisão minoritária junto aos tribunais brasileiros.

Por outro lado, existem posicionamentos doutrinários e jurisprudenciais que defendem a tipificação da conduta em destaque junto ao artigo 121 do Código Penal, fundamentando a decisão na concepção do dolo eventual.

\section{REFERÊNCIAS}

BRASIL. Constituição (1988). Constituição da Republica Federativa do Brasil.

MORAES, Alexandre de. Direito Constitucional. 17. Ed. São Paulo: Atlas, 2005.

BRASIL. Código de Trânsito (1997) Código de Trânsito Brasileiro.

BITENCOURT, Cezar Roberto. Manual de Direito Penal: Parte Geral. v.1. 7ạ ed. rev. e atual. São Paulo: Saraiva, 2002.

BRASIL. Código Penal Brasileiro.

MACIEL FILHO. E. B. Revista Jurídica - Conceito Jurídico. Disponível em: <http://afrobrasileiros.net.br/wp-content/uploads/2018/04/Conceito-Jur\%C3\%ADdico-14-B.pdf> Acesso em 30 de julho de 2018.

BITENCOURT, C. R. Tratado de Direito Penal: 14. Ed. São Paulo: Saraiva. 2014.

CAPEZ, F. Curso de Direito Penal: legislação penal especial. 9. ed. São Paulo: Saraiva. 2014. ESTEFAM, A. Direito Penal. 3. ed. São Paulo: Saraiva, 2015.

BRASIL. Tribunal de Justiça do Mato Grosso do Sul. Apelação Criminal n. 00319852820108120001. Relator: Des. Dorival Moreira Dos Santos.

BRASIL. Superior Tribunal de Justiça. Recurso Especial n. 705.416/SC. Relator Ministro Paulo Medina. Publicado 20/08/2017. 
BRASIL. Superior Tribunal de Justiça. Recurso Especial n.1.224.263 / RJ. Relator Ministro Jorge Mussi. Publicado 29/04/2011. 